\title{
The Marden-Walker syndrome
}

\author{
CHARLES R. KING AND ELLEN MAGENIS
}

From the Department of Obstetrics and Gynecology, and the Division of Medical Genetics, University of Oregor Health Sciences Center, Portland, Oregon, USA

SUMMARY The characteristic facies, joint contractures, muscular hypotonia, and growth and developmental delay of the Marden-Walker syndrome were present in a 19-month-old boy. Extensive evaluation of the neuromuscular system failed to identify a specific abnormality. Electromyograph居 was normal with low amplitude. Light and electron microscopy of a skeletal muscle biopsy was். normal. Histochemical study of this biopsy material was also normal. The pathogenesis of the syndrome is discussed.

The Marden-Walker syndrome was first defined by Marden and Walker in 1966. In the past 10 years 5 additional patients have been identified (Fitch $e$ t al., 1971; Temtamy et al., 1975; Passarge, 1975; Simpson and Degnan, 1975). Retrospectively, the patients reported by Younessian and Ammann (1964) and Gellis (1963) have features of this syndrome. The infant described by Ealing (1944) may be the earliest description of the Marden-Walker syndrome. We report an additional patient with this syndrome.

\section{Case report}

The proband was born at 42 weeks' gestation after a pregnancy complicated only by a maternal weight gain of $21 \mathrm{~kg}$. Birthweight was $2700 \mathrm{~g}$ with a length of $48.5 \mathrm{~cm}$. Facial features were not specifically noted as dysmorphic at birth, but bilateral talipes equinovarus and camptodactyly of the fingers were noted. Delay of growth and development was apparent by 9 months of age. No unusual health problems were observed. The foot deformity was easily corrected with casting.

At present (19 months) the patient is below the third centile for all growth parameters: height, $76 \mathrm{~cm}$; weight, $7.7 \mathrm{~kg}$; and head circumference, $44.8 \mathrm{~cm}$. Developmentally, the child rolls front to back and back to front. He sits unsupported for short periods of time. He rises on hands and knees. He does not crawl, but attempts to scoot. He does not stand alone or walk. He makes one or two distinct sounds, but not specific words.

The family history is negative for other individuals with a similar phenotype or partial manifestation of

The authors were supported by grants from the National Institutes of Health for a Genetics Study Center (NIH 10820004 08); and a grant for a Mental Retardation Training Program No. 920.

Received for publication 21 November 1977 the syndrome. The mother's age at delivery was $28-$ years, as was the father's. The mother has a normalo daughter by a previous marriage. The first 2 pregnan-0 cies of the present marriage resulted in first trimester@ spontaneous abortions.

PHYSICAL EXAMINATION (FIg. 1 AND 2) The mouth was small. Blepharophimosis with aO depressed nasal bridge and a small nose were present. Intermittent exotropia was observed. The ears were marginally low set and the neck was short. Theo anterior fontanelle was $2 \mathrm{~cm}$ in diameter by palpation. Partly because of a decreased muscle mass, the trunk appeared large in relation to the small extremities. $A \frac{O}{3}$ grade $2 / 6$ systolic ejection murmur was heard along the lower left sternal border. No organomegaly was present. The genitalia were normal, with descended. testes. The neurological examination was grossly normal except for developmental delay, mild: hypotonia, and mildly decreased reflexes. Camptodac -3 tyly of the left third and fourth digits and the righto third digit at the proximal interphalangeal joints was observed. The fingers demonstrated arachnodactyly, 0 and a unilateral transverse palmar crease was noted.

LABORATORY STUDIES

A complete blood count, urine analysis, and SMAC-200 were within the normal range. Metabolic screening of blood and urine was negative. Screeningo chromatography was normal. Creatinine clearancew was $100 \mathrm{ml} / \mathrm{min}$ per $\mathrm{m}^{2}$. A normal 46, XY karyotype was found with phytohaemaglutinin-stimulatedo peripheral lymphocytes and quinacrine banding.

RADIOLOGICAL STUDIES

The chest $x$-ray, IVP, barium enema, and skull films were normal. Bone age was 2 SD below the mean for 


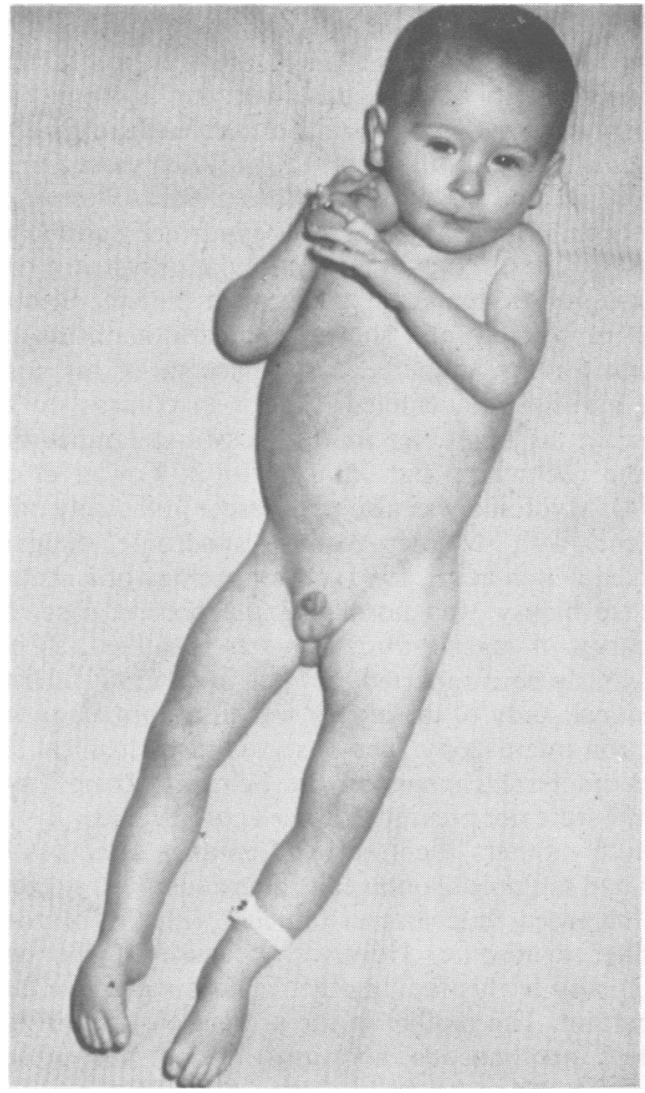

Fig. 1 The proband at 19 months of age.

18 months of age. Bilateral radioulnar synostosis was noted.

\section{NEUROMUSCULAR STUDIES}

An electroencephalogram was abnormal, showing a repetitive spiking focus in the occipital area, most marked on the right side. Electromyography of the left gastrocnemius, tibialis anterior, and biceps, produced a wave form with low amplitude and brief action potentials. No fibrillations or fasciculations were noted. No myotonic discharges were found on electromyography. Muscle biospy showed uniform diameter fibres with no necrosis, regeneration, or inflammation. Both histochemical type I and type II muscle fibres were present in a normal chequerboard pattern. No intracellular inclusions were seen with trichrome stain. Oxidative enzyme preparations were normal. Electron microscopy was normal.

\section{Discussion}

In 1966, Marden and Walker described a $2600 \mathrm{~g}$ girl with dysmorphic facies and severe blepharophimosis.

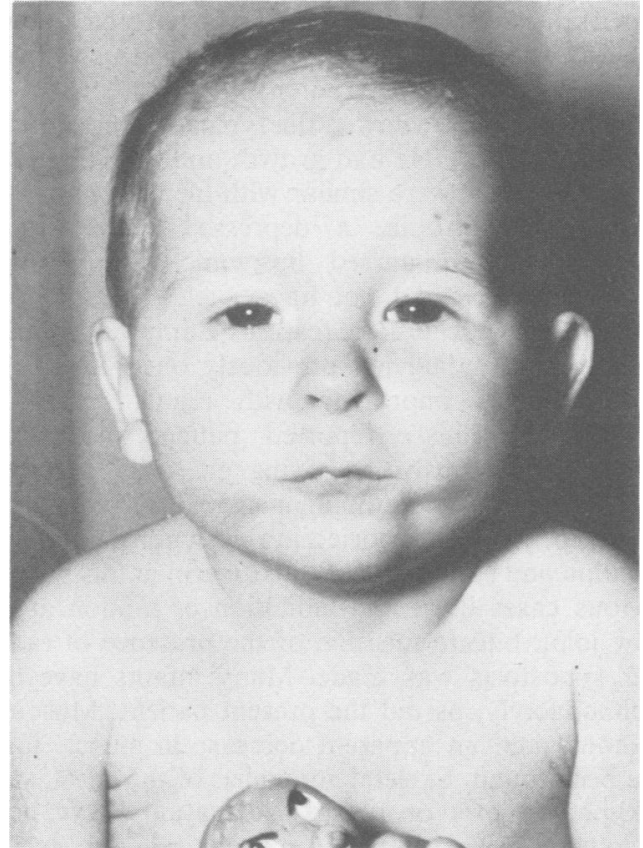

Fig. 2 Facial features of the patient.

The infant had joint contractures, arachnodactyly, growth and developmental delay. She died at 3 months of age from pneumonia. The necropsy identified microcystic kidneys and an anomalous connection of the inferior vena cava with the superior vena cava. This infant was considered to represent a new clinical entity, though some of the child's features were similar to those of the Schwartz-Jampel syndrome (Schwartz and Jampel, 1962; Aberfield et al., 1970).

A second infant was reported by Fitch et al. (1971). This child had facies similar to the patient reported by Marden and Walker. Joint contractures, muscular hypotonia, and growth and developmental delay were also present. Pneumoencephalography showed reduced size of the brain stem and cerebellum, but not hypoplasia. Evaluation of the neuromuscular system with muscle biopsy and electromyography was performed. Again the syndrome was compared to the Schwartz-Jampel syndrome.

From Egypt, 2 first cousins with the same general phenotypic findings were identified (Temtamy et al., 1975). This is the only familial occurrence of this syndrome reported so far. The family exhibited signifcant consanguinity. These findings suggest the possibility that this syndrome may be an autosomal recessive condition. Additional case reports in 1975 show similar phenotypic features (Passarge, 1975; Simpson and Degnan, 1975). The previously noted cases reported by Ealing (1944), Gellis (1963), and 
Younessian and Ammann (1964), have some features of the Marden-Walker syndrome, but retrospectively the diagnosis is difficult to confirm.

The present case showed the typical features of this syndrome (Table). He had growth and developmental delay. The facies were similar with blepharophimosis, intermittent exotropia, a depressed nasal bridge, microstomia with pursed lips, micrognathia, and microcephaly. He did not have a cleft palate. Joint contractures were also a feature. Camptodactyly of the fingers, a finding not previously observed in this syndrome, was improving with regular extension exercises. Previously reported patients have also shown spontaneously improving or easily corrected joints contractures. Radioulnar synostosis, which has not previously been reported in this syndrome, limited pronation and supination of the forearm in this patient. Previous cases have had limitation of motion at the elbow joint, but no mention of the presence of radioulnar synostosis was made. Many infants have had arachnodactyly, as did the present patient. Muscular hypotonia and an apparent decrease in muscle mass have been found. Skeletal anomalies of the chest, such as kyphoscoliosis or pectus excavatum, have been previously observed, but were not present in this patient.

Major visceral anomalies have been identified in the kidney, heart, and brain in previously reported patients. Only the original patient reported by Marden and Walker (1966) showed renal anomalies. No other patients have had histological study of the kidneys. The present infant had a normal intravenous pyelogram, urine analysis, and creatinine clearance. He also had a cardiac murmur. The Marden-Walker patient had a cardiovascular anomaly of the inferior vena cava. One of the patients reported by Temtamy et al. (1975) had dextrocardia. All of the patients had manifest developmental delay, but only the patien reported by Fitch et al. (1971) showed a structura $\vec{P}$ abnormality of the central nervous system. The present child had an abnormal electroencephalogram.

Because of similarities to the Schwartz-Jampe syndrome, and because a previous patient (Fitch et al. 1971) with the Marden-Walker syndrome had muscles abnormalities, the neuromuscular system was thoroughly evaluated in the present patient. Electro-n myography did not show significant abnormalities. except for low amplitude. No evidence of myotonia was induced or identified. This is in contrast to the $\vec{\omega}$ presence of myotonia in the Schwartz-Jampel syn-o drome (Schwartz and Jampel, 1962; Fowler et al. 1974). Myotonia was also not present in the only other? patient with Marden-Walker syndrome similarlyer studied (Fitch et al., 1971). The histology of a skeletaj muscle biopsy was normal in the present case. Noo disparity of muscle fibre size was identified, as had previously been reported by Fitch et al. (1971). Histo? chemical study of the biopsy was also normal, as was $\overrightarrow{ }$ electron microscopy. The observed histochemical ando ultrastructural changes of the Schwartz-Jampel syn $\frac{0}{0}$ drome were not present (Fowler et al., 1974).

Both mothers reported by Temtamy et al. (1975) $\overrightarrow{0}$ had had multiple spontaneous abortions. This suggests an increased fetal loss in families with the Marden Walker syndrome. However, because of the con-o sanguinity in this family other factors may have beens important. The mother in the present case report hado had 2 spontaneous abortions during her presento marriage. None occurred during a previous marriage from which she had a normal daughter. This further $\overrightarrow{\overrightarrow{0}}$ suggests there may be an increased fetal loss with this syndrome.

Since only 1 instance of multiple family members? with the Marden-Walker syndrome has been reported,

Table Phenotypic features of Marden-Walker syndrome

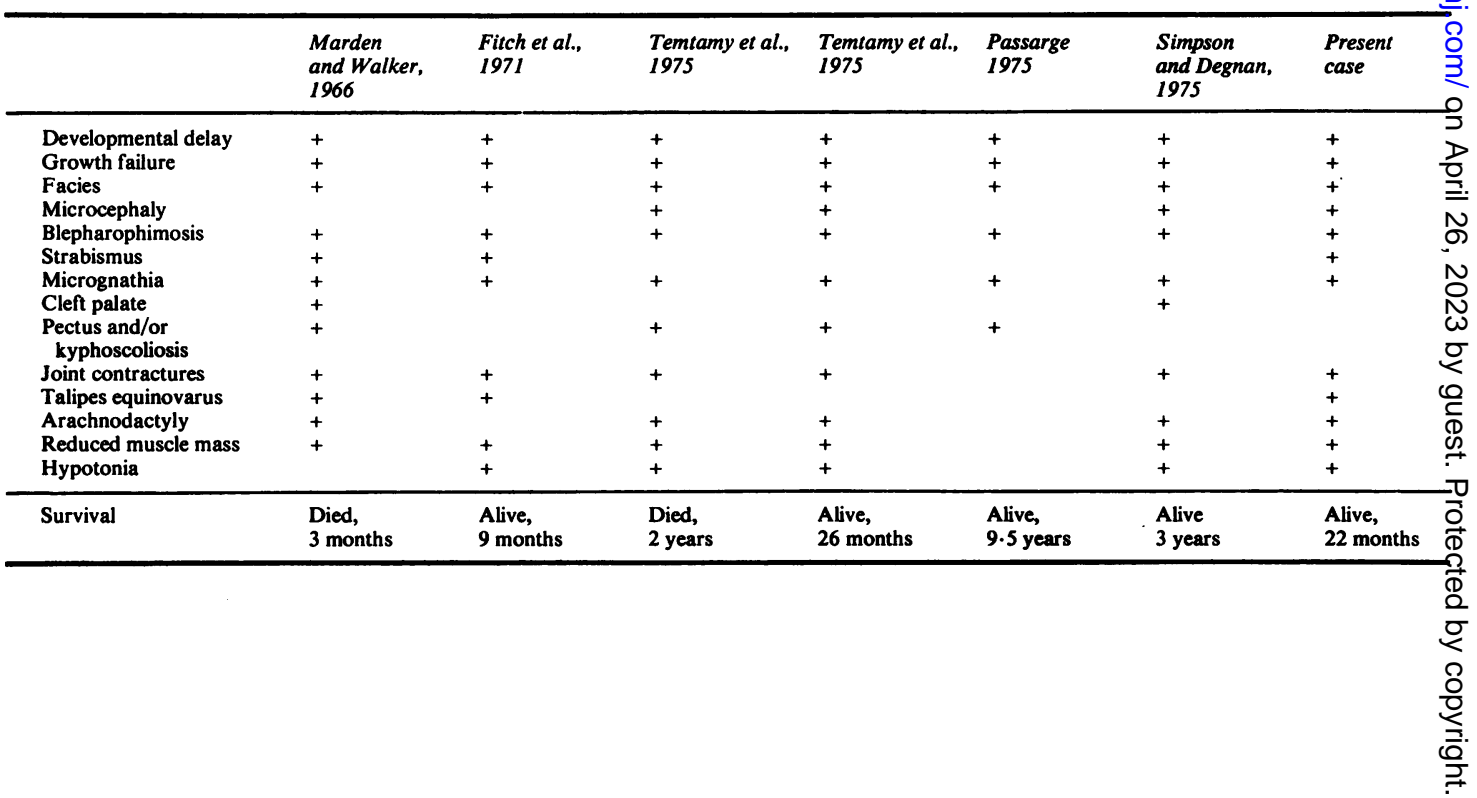


the genetic nature of the disease is far from clear. The Egyptian family reported by Temtamy et al. (1975) was consanguineous with 2 affected first cousins. This, of course, suggests autosomal recessive inheritance. The mean maternal age of 27 years, and the mean paternal age of 33 years in reported parents are above that of the general population. Advanced paternal age has been postulated as an important factor in new dominant mutations (Jones et al., 1975). The mean paternal age in patients with this syndrome is similar to that observed in other known autosomal dominant conditions such as achondroplasia (Jones et al., 1975). The present case is compatible with autosomal recessive inheritance, a new autosomal dominant mutation, or sporadic occurrence. Additional families must be studied to provide the necessary data for correct interpretation of the mode of inheritance.

\section{References}

Aberfield, D. C., Mamba, T., Vye, M. V., and Grob, D. (1970). Chondrodystrophic myotonia: report of two cases. Myotonia, dwarfism, diffuse bone disease, and unusual ocular and facial abnormalities. Archives of Neurology, 22, 455-462.

Ealing, M. I. (1944). Amyoplasia congenita causing malpresentation of the foetus. Journal of Obstetrics and Gynaecology of the British Empire, 15, 144-146.

Fitch, N., Karpati, G., and Pinsky, L. (1971). Congenital blepharophimosis, joint contractures, and muscular hypotonia. Neurology, 21, 1214-1220.

Fowler, W. M., Layzer, R. B., Taylor, R. G., Eberle, E. D., Sims, G. E., Munsat, T. L., Philippart, M., and Wilson, B. W. (1974). The Schwartz-Jampel syndrome. Its clinical, physiological and histological expressions. Journal of the Neurological Sciences, 22, 127146.
Gellis, S. S. (Editor) (1963). Year Book of Pediatrics, p. 193. Year Book Medical Publishers, Chicago.

Jones, K. L., Smith, D. W., Harvey, M. A. S., Hall, B. D., and Quan, L. (1975). Older paternal age and fresh gene mutation: data on additional disorders. Journal of Pediatrics, 86, 84-88.

Marden, P. M., and Walker, W. A. (1966). A new generalized connective tissue syndrome. American Journal of Diseases of Children, 112, 225-228.

Passarge, E. (1975). Marden-Walker syndrome. Birth Defects: Original Article Series, 11, 470-471. The National FoundationMarch of Dimes, New York.

Schwartz, O., and Jampel, R. S. (1962). Congenital blepharophimosis associated with an unique generalized myopathy. Archives of Ophthalmology, 68, 52-57.

Simpson, J. L., and Degnan, M. (1975). A child with facial and skeletal dysmorphia reminiscent of Schwartz syndrome. Birth Defects: Original Article Series 11, 456-458. The National Foundation-March of Dimes, New York.

Temtamy, S. A., Shoukry, A. S., Raafat, M., and Mihareb, S. (1975). Probable Marden-Walker syndrome: evidence for autosomal recessive inheritance. Birth Defects: Original Article Series, 11, 104-108. The National Foundation-March of Dimes, New York.

Younessian, S., and Ammann, F. (1964). Deux cas de malformations cranio-faciales. 1. Microphthalmie (nanisme oculopalpebral) avec dysostose cranio-faciale et status dysraphique. 2. Dysmorphic mandibulo-oculo-faciale (syndrome d'HallermannStreiff). Ophthalmologica, 147, 108-117.

Requests for reprints to Dr Charles R. King, Department of Obstetrics and Gynecology, University of Kansas Medical Center, 39th and Rainbow, Kansas City, Kansas 66103, USA. 